\title{
Energy Content Of The Domestic Wastewater Sludge Dried In The Thermal Dryer
}

\author{
Zakaria M.S ${ }^{1,}{ }^{*}$, Suhaimi Hassan ${ }^{2}$, and Faizairi M.N. ${ }^{1}$ \\ ${ }^{1,2}$ Faculty of Mechanical, UTP, Malaysia
}

\begin{abstract}
Domestic Wastewater Sludge (DWS) is considered as one of the largest contributor waste in Malaysia. Converting this waste as an alternative fuel can eliminate the disposal problem and reduce the environmental issue that causes by this waste. However, the initial moisture content in DWS is around $90 \%$ and in order to convert this waste into useful solid fuel, the moisture content of this waste must be reduced to $20 \%$ and below. Thermal dryer is one of the efficient dryer for the DWS that is capable of drying the huge volume of DWS in a short period of time. This study focused on the energy usage by the thermal dryer with several operating condition and the effect to the Higher Heating Value (HHV) of DWS. Based on the study, the higher heating value of DWS obtained from the experimental of thermal dryer found to be comparable with the results obtained from other biomass types which is around 9-15.86 MJ/kg. After analysis and comparison of the energy from the dried DWS and energy consumed by the dryer, the best operating condition of the thermal dryer was at $275 \mathrm{~kW}$ of power rating with speed of 30 and $10 \mathrm{rpm}$ (revolution per minute) of the screw conveyor in the feeder and dryer respectively.
\end{abstract}

\section{Introduction}

The demand of energy in Malaysia is rapidly increasing align with the growth of population, industrial and economy. Malaysian's population is expected to reach 33.4 million and 37.4 million by the year of 2020 and 2030 respectively [1-2]. The energy consumption of the country keeps increasing due to the increase in economic growth as well as the population. Energy consumption is also being influenced by the demands of the transportation, industry, commercial and residential sectors. Fossil fuel has become the main source for electricity generation and this fuel has been heavily used for the past few decades in Malaysia and the high dependence on this fossil fuel source creates a huge challenge in the energy and power sector of the country [3]. It is well-known that the fossil fuel is a nonrenewable energy which is not sustainable. Among all the renewable energy sources, biomass is considered as an alternative energy source that could solve the high dependency on the fossil fuel, economic growth and environmental benefits. The term biomass represents all organic materials derived from organic matter (wood, crops, etc.), food processing, animal manure and municipal solid waste [4]. Biomass has significant features such as it is renewable, inexpensive and produces low emissions of greenhouse gases [5]. In addition,

\footnotetext{
*Corresponding author: mohd16005855@utp.edu.my
} 
biomass material is the only renewable energy source that can be converted into convenient solid, fluid and gaseous fuel [6-13]. However, the main hurdle of DWS is moisture content in the DWS which is more than $85 \%$ as reported by Deng [14]. In any type of biomass, the moisture content in is considered one of the important factors in the combustion process. This is because high moisture content will produce low combustion efficiency due to ignition difficulty, as large amount of energy would be used for water vaporization [15]. As a result, the sustainability of combustion will be affected [16-19]. Based on the previous study, the conventional oven dryer that is widely used by previous researcher to dry DWS only suitable for lab scale, requiring longer times and consuming much energy. Therefore, further study is required to develop a dryer that can be used to dry a larger scale of DWS's with the aim to reduce its moisture content to below $20 \%$. One of the efficient dryer available for the DWS drying system is thermal dryer. Thermal dryer capable to reduce the moisture content in the DWS into acceptable level in short time. The effect of operation condition to the energy consumption of thermal dryer and higher heating value of DWS was investigated to determine the optimum operating condition for the thermal dryer.

\section{Methodology}

The sample of treated sewage sludge was collected from the sewage treatment plant at Bunus waste water treatment plant. Thermal dryer used for drying the DWS developed in this study was a screw type thermal dryer which consisted of two main components; the feeder and dryer. The dimensions (length and diameter of the screw conveyor) of the screw type thermal dryer were taken from the design developed by Arlabosse et. al [20], with some minor modifications. This include the using of inclined feeder, continuous inlet for dryer and utilizing the hot gas from the dryer to heat the feeder. Figure 1 show the schematic diagram of the screw type thermal dryer that used in this study.

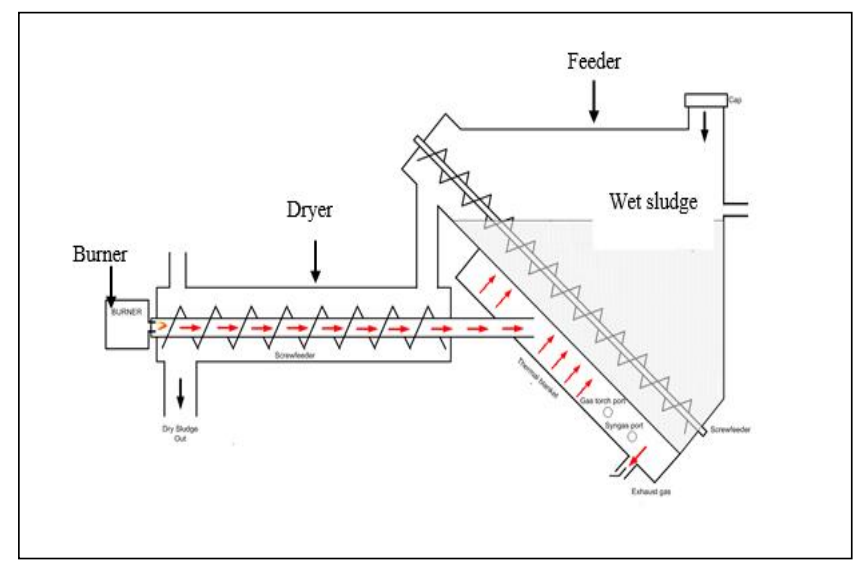

Fig. 1. Schematic diagram of screw type thermal dryer

In this type of thermal dryer, the DWS is fed into the dryer chamber by the screw conveyor in the feeder chamber. A heat transfer medium which is hot gas provided by the burner is circulated through the dryer chamber and the hollow structure of the rotating assembly to provide the thermal energy required to evaporate the water in the DWS. The screw conveyor in the dryer chamber transported the DWS into the outlet as the final product of the thermal dryer. 
Each of the experiment was conducted for 3 times and the results were obtained by the average value. Total production rate, fuel consumption and electric energy from the experiment were converted into mega joule per hour $(\mathrm{MJ} / \mathrm{h})$. The total output energy from the thermal dryer was the energy from its product. The dried DWS from the thermal dryer will be converted into useful solid fuel for energy generation purpose. The total energy gained by the dried DWS from the thermal dryer can be calculated as in the equation (1) below [18]:

Total energy gained $(\mathrm{MJ} / \mathrm{h})$ : The HHV $(\mathrm{MJ} / \mathrm{kg}) \times$ Production rate $(\mathrm{kg} / \mathrm{h})$

In the experiment of the thermal dryer, there were 6 different power ratings of the burner and each of the power rating had different fuel consumptions. The fuel consumption of the burner was recorded for each power rating and the energy consumption by the burner was considered as the input energy. The diesel consumption was recorded in liter per hour $(1 / \mathrm{h})$ and converted to mega joule per hour $(\mathrm{MJ} / \mathrm{h})$ in order to standardize the unit for comparison purposes. The conversion of diesel energy to $\mathrm{MJ} / \mathrm{h}$ was using equation (2) below [19]:

Energy Consumption (MJ/h): Fuel consumption (1/h) x $34.3(\mathrm{MJ} / \mathrm{l})$

The optimum operating condition for the thermal dryer was selected by identifying the operating condition that consumed lower energy and produced the acceptable level of moisture content in the DWS.

\section{Results and discussion}

There were various power ratings, speeds of both screw conveyor in the feeder and the dryer that were applied to the thermal dryer. Therefore, all the samples obtained from each operating condition will be tested in the bomb calorimeter in order to study the effects of each operating condition to the HHV of the DWS.

\subsection{Higher heating value}

Figure 2 represent the HHV of the dried DWS at the optimum operating condition. It can be seen that high-power rating produced lower HHV of dried DWS while the low power rating produced higher HHV of dried DWS. From the proximate analysis, high power rating gave high temperature to the thermal dryer, hence diminishing the volatile matter in the DWS and increasing the ash content. Therefore, the HHV of DWS was decreased with the increase of the power rating in the burner. Besides that, high speed of the screw conveyor in the feeder and dryer gave higher HHV compared to the lower speed. This was because the high speed of the feeder and dryer will reduce the drying time of DWS, hence the volatile matter in the DWS was less diminished at higher speed compared to the lower speed of the screw conveyor.

\subsection{Output energy}

Figure 3 show the output energy versus power rating of the burner in the thermal dryer with various speeds of the screw conveyor in the dryer and feeder at optimum operating condition. In general, the total output energy from the thermal dryer increased to be directly proportional to the speed of the screw conveyor in the feeder and dryer. This was due to the high speed of the screw conveyor which will result in a high production rate of DWS. However, the output energy showed a clear trend of decreasing as the power rating of the 
burner increased. This was due to low HHV produced by high temperature in the thermal dryer. Based on the results obtained, it can be seen that the highest output energy was identified at the highest speeds of the screw conveyor in the feeder and dryer which were 10 and $30 \mathrm{rpm}$ respectively with $135 \mathrm{~kW}$ of power rating. Meanwhile, the lowest output energy was identified at the lowest speeds of the screw conveyor for both feeder and dryer which were 2 and $6 \mathrm{rpm}$ respectively with $310 \mathrm{~kW}$ of power rating. To summarize, the output energy was highly dependent on the production rate of the thermal dryer as well as the power rating of the burner.

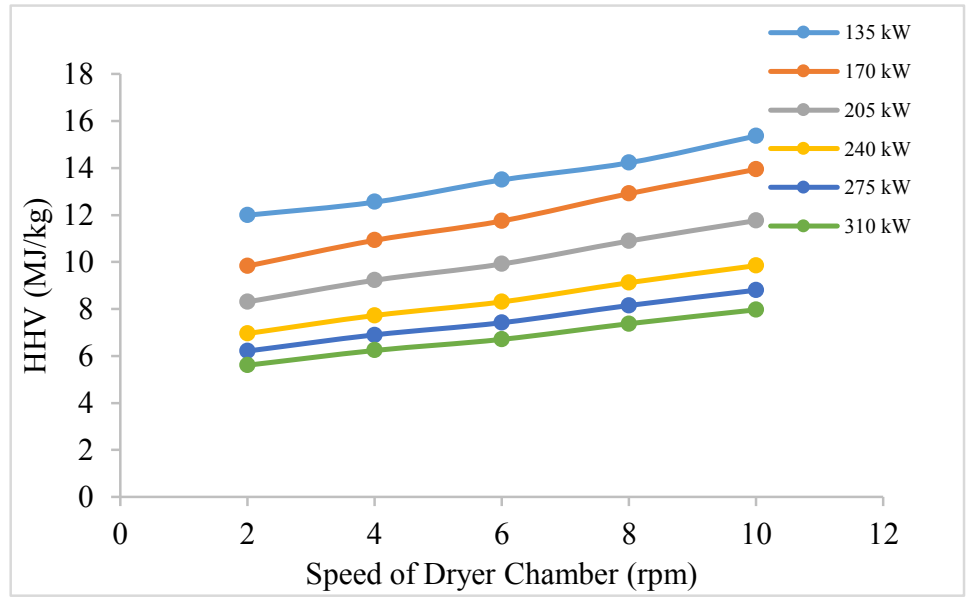

Fig.2. HHV of DWS with various speed of dryer chamber and power rating of the burner.

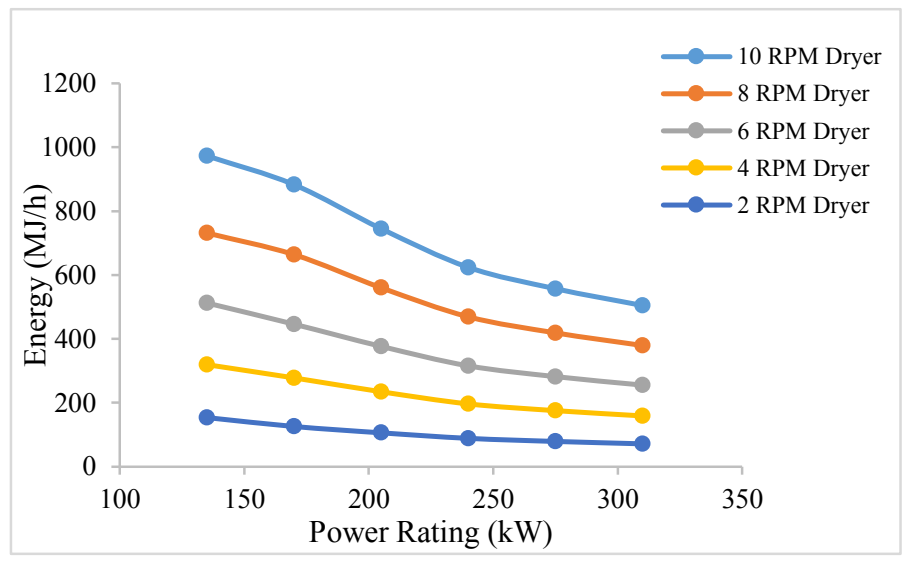

Fig. 3. The output energy of the thermal dryer with variation of power rating and speed of the dryer at speed of feeder $30 \mathrm{rpm}$.

\subsection{Energy comparison between input and output energy}

In this section, only selected results were displayed and compared. The selected optimum condition was based on the lowest gap between the input and output energy of the thermal dryer with product od dried DWS less than $20 \%$ of moisture content. Figure 4 show the selected results for the comparison between the input and output energy of the thermal dryer with the speeds of the screw conveyor in the feeder at $10 \mathrm{rpm}$. The optimum condition 
for the $30 \mathrm{rpm}$ of the feeder was identified at $10 \mathrm{rpm}$ of the dryer with $275 \mathrm{~kW}$ of power rating, where the highest input and output energy for this operating condition were 1014.56 $\pm 15.21 \mathrm{MJ} / \mathrm{h}$ and $556.66 \pm 4.56 \mathrm{MJ} / \mathrm{h}$ respectively.

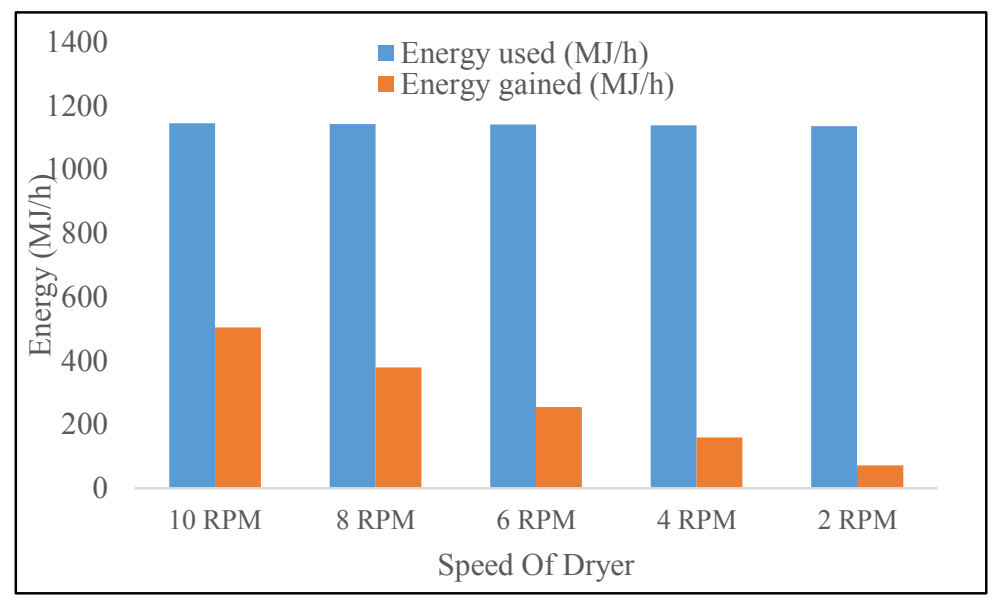

Fig.4. Energy comparison at optimum operating condition of thermal dryer.

\section{Conclusions}

As conclusion, the optimum condition for the thermal dryer was at the lowest gap between the input and output energy which is $30 \mathrm{rpm}$ of the feeder and $10 \mathrm{rpm}$ of the dryer with $275 \mathrm{~kW}$ of power rating.

\section{References}

1. R. Ali, I. Daut, and S. Taib, "A review on existing and future energy sources for electrical power generation in Malaysia," Renewable and Sustainable Energy Reviews, vol. 16, no. 6, pp. 4047-4055. (2012).

2. A. M. Omer, "Energy, environment and sustainable development," Renewable and Sustainable Energy Reviews, vol. 12, no. 9, pp. 2265-2300, (2008).

3. S. M. Shafie, T. M. I. Mahlia, H. H. Masjuki, and a. Ahmad-Yazid, "A review on electricity generation based on biomass residue in Malaysia," Renewable and Sustainable Energy Reviews, vol. 16, no. 8, pp. 5879-5889, (2012).

4. T. H. Oh, S. Y. Pang, and S. C. Chua, "Energy policy and alternative energy in Malaysia: Issues and challenges for sustainable growth," Renewable and Sustainable Energy Reviews, vol. 14, no. 4, pp. 1241-1252, (2010).

5. S. Ahmad and R. M. Tahar, "Selection of renewable energy sources for sustainable development of electricity generation system using analytic hierarchy process: A case of Malaysia," Renewable Energy, vol. 63, pp. 458-466, (2014).

6. Z. Z. Noor, R. O. Yusuf, A. H. Abbas, M. A. Abu Hassan, and M. F. Mohd Din, "An overview for energy recovery from municipal solid wastes (MSW) in Malaysia scenario," Renewable and Sustainable Energy Reviews, vol. 20, pp. 378-384, (2013).

7. H. C. Ong, T. M. I. Mahlia, and H. H. Masjuki, "A review on energy scenario and 
sustainable energy in Malaysia," Renewable and Sustainable Energy Reviews, vol. 15, no. 1, pp. 639-647, (2011).

8. S. Mekhilef, R. Saidur, A. Safari, and W. E. S. B. Mustaffa, "Biomass energy in Malaysia: Current state and prospects," Renewable and Sustainable Energy Reviews, vol. 15, no. 7, pp. 3360-3370, (2011).

9. A. Abdalla, "Development of Fuel Briquettes From Biomass Residue," Universiti Teknologi Petronas, Master Thesis. (2013).

10. J. Ma, Z. Wang, C. Zhu, Y. Xu, and Z. Wu, "Electrogenesis reduces the combustion efficiency of sewage sludge,” Applied Energy, vol. 114, pp. 283-289, (2014).

11. Y.Yang, J. G. Brammer, J. Samanya, A. K. Hossain, and A. Hornung, "Investigation into the performance and emissions of a stationary diesel engine fuelled by sewage sludge intermediate pyrolysis oil and biodiesel blends," Energy, vol. 62, pp. 269276, (2013).

12. D. Fytili and A. Ã. Zabaniotou, "Utilization of sewage sludge in EU application of old and new methods - A review," Renewable and Sustainable Energy Reviews, vol. 12, pp. 116-140, (2008).

13. A. H. Molla, A. Fakhru'l-Razi, S. Abd-Aziz, M. M. Hanafi, P. K. Roychoudhury, and M. Z. Alam, "A potential resource for bioconversion of domestic wastewater sludge," Bioresource Technology, vol. 85, no. 3, pp. 263-272, (2002).

14. T. Deng, M. P. M. Lim, Z. M. Noor, and N. Abdullah, "Ecotoxicology and Environmental Safety Vermiremoval of heavy metal in sewage sludge by utilising Lumbricus rubellus," Bioresource Technology, vol. 90, pp. 13-20, (2013).

15. M. Z. Alam, S. A. Muyibi, and R. Wahid, "Statistical optimization of process conditions for cellulase production by liquid state bioconversion of domestic wastewater sludge," Bioresource Technology, vol. 99, no. 11, pp. 4709-4716, (2008).

16. A. Magdziarz and S. Werle, "Analysis of the combustion and pyrolysis of dried sewage sludge by TGA and MS," Waste Management, vol. 34, no. 1, pp. 174-179, (2014).

17. J. Zhou, T. Li, Q. Zhang, Y. Wang, and Z. Shu, "Direct-utilization of sewage sludge to prepare split tiles," Ceramics International, vol. 39, no. 8, pp. 9179-9186, (2013).

18. C. C. Xu and J. Lancaster, "Treatment of Secondary Sludge for Energy Recovery," Europe, (2007).

19. H. Cheng and Y. Hu, "Municipal solid waste (MSW) as a renewable source of energy: Current and future practices in China," Bioresource Technology, vol. 101, no. 11, pp. 3816-3824, (2010).

20. P. Arlabosse, G. D. Imporzano, G. Garuti, M. Negri, and F. Adani, "Science of the Total Environment Sanitation ability of anaerobic digestion performed at different temperature on sewage sludge," Science Total Environment, vol. 466-467, pp. 888897, (2014). 